\title{
Exploring the Concept of Crisis in Businesses: a Critical Step in the Formulation and Implementation of Crisis Management
}

\author{
Radu-Cristian MUȘETESCU \\ Bucharest University of Economics, Romania \\ radu.musetescu@rei.ase.ro \\ Hezi-Aviram SHAYB \\ Bucharest University of Economics, Romania \\ shaybhezi@gmail.com
}

\begin{abstract}
After an initial period of ignorance of the phenomenon of crises that are experienced by businesses, a fast expanding literature is approaching this issue. However, the present authors perceive a lack of commonly agreed conceptualization and taxonomy in debating the situations when companies are facing difficulties. We explore in this paper how economic theory and management knowledge could assist escaping such challenging contexts. We argue that a narrow focus on financial indicators of the company is critical for any business decision targeting the restructuring and reorganization but the deep causes of the challenging context should be identified. We argue that crisis management has in common principles and approaches with risk management but the delimitation should be made clear. There may be organizational crisis when risk management approaches could be employed in order to deal with them but there are many instances when the approach of risk management is insufficient or even not operational. Such circumstances require a real entrepreneurial approach. We advance a coherent system of conceptualizing the crisis and differentiating crisis management from risk management.
\end{abstract}

Keywords: crisis, risk, uncertainty, entrepreneurship, business failure

\section{Introduction}

The concept of crisis is maybe among the most used and abused concepts in social sciences. It may be similar as in the case of concepts like "power", "competition" or "risk". What is striking is that it has a broad coverage in different disciplines starting from economics or political science to biology or psychology.

We could wonder whether the phenomenon of "crisis" could emerge in nature independent of human action and contemplation. It could be somehow strange to argue that the 7.5-mile-wide asteroid that hit the Earth surface 66 million years ago (in fact, the ocean, near present-day port town of Chicxulub, Mexico) and caused some climate changes (in fact, a global cooling) that determined the mass extinction of three quarters of life generated, in fact, a crisis in the ecosystem of the planet. Or there is a crisis, in abstractum, of water in Sahara. Conditions and process taking place in nature, however extraordinary they could seem, could not be qualified as "crises".

Change is embedded in nature and extreme change is also a part of the natural processes in the environment. Dima and Vasilache (2016) mentions there are some countries, like Belgium, France or Malta, more open to change than others. Assuming no impact on human population and property, it is somehow strange to argue that a certain hurricane or a tsunami caused a crisis in the natural environment. We could argue, in this respect, that the contemplation of a "crisis" needs a human agency that contemplates it. Even 
more, the concept of crisis needs also an impact on human-made environment or, what could be called in economics, capital goods. If an individual admires from a plane a hurricane in the middle of the Atlantic Ocean, with assumed no immediate impact on human lives or stock of capital, we could argue about whether there is any "crisis" in the middle of the ocean. There is no crisis when extreme weather impacts the South Pole or a gigantic sandstorm hits the middle of the Sahara desert where there is no human life nor activity.

PICBE | 963

It is very interesting to point that the origin of the term "crisis" is from the Greek "krinein" (engl. "to decide") and "Krisis" (engl. "decision"). Later, in late Middle Ages, the concept started to denote "a decisive moment", that is, a moment that needs a decision. Such an origin is very challenging as it suggests the human agency and the need for human choice and, later, action.

\section{Literature review}

Speaking about industrial crisis, Paul Shrivastava argues that "[industrial] crisis are situations in which dysfunctional effects of industrial activities cause major damage in human life and natural environment and major social disruptions ... crises extend beyond their immediate organizational sphere to encompass economic, social crisis threatening the survival of social structures and institutions" (Shrivastava, 1987, p. 200). He further argues that "all triggering events and subsequent crisis cause large damage (or perceptions of large damage) to human life and natural environment. They also create unknown risks to the public, which further enhances the perceptions of damage" (Shrivastava, 1987, p. 201).

Alexander Kouzmin admits that there is a significant problem in defining a crisis: "contestation over definitions continues to bedevil, almost inevitably, within the academy and among practitioners. Temporary consensus, when it exists, is precarious and likely to evaporate with a blink of a published eye ... operationalizing a precarious consensus of a definition, which encompasses disasters/tragedies/emergencies/crisis has been problematic" (Kouzmin, 2008, p. 158). Kouzmin seems to adopt the definition of the crisis such as exposed by Rosenthal, Charles and Hart that "crisis events feature: (1) a severe threat or an unfavorable, destructive, and often life-threatening change to the victim's environment; (2) a high degree of uncertainty; (3) the need for prompt, yet critical and potentially irreversible, decisions" (Kouzmin, 2008, p. 158). So uncertainty, ambiguity and risk are among the core elements to be taken into consideration in the process of defining a crisis.

The same Kouzmin admits that the process of defining a crisis may take several perspectives into consideration. For example, from a management perspective, crisis are instances when there is "a discretionary management" perspective: crisis events occur whenever there is seizure of the existing mechanisms of functionality; a need for a major resource (re)distribution; and/or a constituency's recognition (perception) of one or both of those events" (Kouzmin, 2008, p. 159).

Pearson and Clair define crisis as "a low probability, high-impact event that threatens the viability of the organization and is characterized by ambiguity of cause, effect, and means of resolution, as well as by a belief that decisions must be made swiftly" (Pearson and Clair, 1998, p. 1997).

Heller and Darling consider that „a crisis is, therefore, an unstable time or state of affairs in which a decisive change is impending - either one with a distinct possibility of a 
highly undesirable outcome, or one with a distinct possibility of a highly desirable and extremely positive outcome" (Heller and Darling, 2012, p. 155).

All these definitions seem to have in common the judgement that the crisis is defined by the impact and the effects. However, this is not a convincing definition. While the assessment of the impact of the crisis allow us to perceive the phenomenon, we must define the concept of "crisis" in an ex ante, logical manner. For example, if we could make a relevant comparison, some economists define the concept of "inflation" as an increase in the Consumer Price Index, that is, the average index of the prices of some consumer goods that form a basket. However, other economists argue that such an increase is only the manifestation of another process which is the expansion of the money supply in relation with the money demand.

Any capital good built by a human has been designed in order to function in a certain way and perform a certain function. The need for digital skills and soft skills can cause a company crisis according to Foerster-Pastor (2018). Anytime that such a capital good does not succeed in fulfilling its function, there emerges a gap in the expectation of the human actors between the planned course of action (according to the design) and the actual course of action. Under such circumstances, there emerges a need to take a decision how to restore the actual condition after the dysfunction in order to obtain a new course of action that leads as close as possible to the intended course of action. Telang (2016) maintains the opinion that communication is the key in such a situation. Obviously, there is always a certain probability that a particular capital good will fail or experience dysfunctions as any human individual expects that nature always leads to extraordinary events or even just consumption of the value of the capital goods that leads to extraordinary failures.

\section{Methodology}

The definition of a "crisis" should offer an ex ante and principle-based account. We could notice that the vast majority of definitions taken into consideration focus primarily on a consequential approach ("consequentialist explanation"). That is, they define the concept through the effects of what are considered "disruptions". In fact, crisis should be recognized not only by what is considered to be ex post effects, after they occur, by their impact, but in the process of their unfolding and, maybe even more, before they start. So can we avoid a primarily empirical approach and offer an ex ante definition.

We consider that a crisis is a gap between expectations of the human agent and the impact of certain processes and phenomena outside the control of the person in question. Under such circumstances, there emerges a need to take a decision how to restore the actual condition after the moment of becoming aware about the gap in order to obtain a new course of action that leads as close as possible to the intended course of action.

As we can see, there are several elements of the definition that we should further explore. The first element is the "expectations" element. Such expectations are formed based on the human understanding of the processes and phenomena and usually they are based on the "normal" functioning of the environment of that particular individual.

The forming of expectations in the human mind is based, at it turn, on several factors:

- the explicit or implicit theory that the human agent adopts regarding the causality between the phenomena and processes around him. Sometimes, individuals experience crisis 
just because they have a wrong theory of causality regarding the processes and phenomenon they are influenced by. In consequence, their forecast will be proven wrong by the processes and phenomena around them;

- bounded rationality: which means, in economics, the inability to comprehend all the phenomena in the future. This is most probably related to the fact that our expectations take also into consideration several factors that operate in the same time and individuals are obliged to make judgements of relevance through which they attempt to anticipate the most probable course of action. As new factors or previously ignored ones become more relevant that the old ones or the relevance of such factors just changes, the gap in expectations is widening.

- information asymmetry: that is, the different access to information from the part of different actors. Under such a circumstance, such actors form different expectations regarding the future and that may lead to a potential conflicting views even if they may share the same theory regarding the causality between processes and phenomena around them.

From these perspectives, individuals and organizations produce different expectations regarding the future evolution of the market as well as their organizations. And from these relationship between the present state of affairs and the future state of affairs, the same individuals and organizations allocate, in order to act, resources in order to reach their objectives and according to their economic calculation.

Any action performed by an individual or organization start from a judgement regarding the ratio between the objectives that are looked after and the resources needed to reach such objectives. Economics has been termed in general the science of scarcity as the means are always in short supply as compared to the ends.

Both ends and means and their ratio are formed based on economic calculation and the expectations of the entrepreneurs regarding the future conditions of the market in which they operate as well as the general environment of business in which they conduct their affairs, starting from the basic natural environment till the anticipated dynamics in the prices of both inputs and outputs.

A crisis is a mismatch between allocated resources and resource consumed by an event out of the control of the individual or the organization we are taking into consideration. Obviously, crisis can be a result of poor plans and the way the organization generates expectations or of external events that make normal plans. And we argue that the plans that individuals and organization are building are essential in the definition of crisis.

The normal operation of a market economy implies a constant change in the supply and demand for any economic good. In consequence, individuals and organization are trying to allocate today the resources expected to be needed in the future. For example, any driver is aware that as he / she drives a car, the gasoline is consumed and, at one moment in the future, he or she will need to refill the tank in order to keep driving. If, as a driver, you forget to check the level of the gasoline in the tank or purely and simply ignore, for various reasons such an aspect, you will witness at one moment a gap between your ends / expectations (you still want to drive the car) and the reality (the car does not keep going because it lacks gasoline). This could be called a crisis, the moment when the mismatch is revealed in reality.

As Hulsmann argued, "error or failure is a permanent condition of the human endeavor. It consists in choosing an alternative for action that is less important (less preferred) than another one that could have been executed instead" (Hulsmann, 1998). 


\section{Results and discussions}

A very interesting consequence of our definition will allow us to make a difference between crisis and risk, which could be useful for a differentiation between crisis management and risk management.

Assume that each year there is a $20 \%$ probability of a powerful hurricane that inflicts massive damage on an agricultural producer. Can we say that such a producer is in crisis? Can we claim that a meteorological phenomenon such as heavy snow that falls each year in February in a certain area causes crisis? The idea that the economy is in state of evenly rotating and anything that causes a disruption or change that may impact an economic agent is a crisis is emptying the content of the concept of crisis.

Risk has been one of the key concepts studied in economics. Knight made a famous differentiation between risk and uncertainty as: „the essential fact is that risk means in some cases a quantity susceptible of measurement, while at other times it is something distinctly not of this character ... It. will appear that a measurable uncertainty, or "risk" proper, as we shall use the term, is so far different from an unmeasurable one that it is not in effect an uncertainty at all. We shall accordingly restrict the term "uncertainty" to cases of the nonquantitive type" (Knight, 1964, p. 20).

From this perspective, we could associate crisis management with uncertainty while risk management with quantitative approach to measure and assess the exposure to known events and probabilities. Both, crisis management and risk management are part of the general domain of organizational management and they both deal with threats that impact the well running of the organization's systems and the wellbeing of its individuals.

According to Gunning an Hanna (2001, p. 815), the core difference between risk management and crisis management lies in the ability of the organization to change and control the causes of the potential losses it is exposed to. While in the case of the risk management, the company has the ability to change and control such causes - and eventually adopt the risk exposure that is suitable and manageable by the organization - in the case of crisis management, such an ability is practically non-existent. Companies have to accept that there are events or phenomena that cannot be controlled or insulated and that crisis will eventually occur. The uncertainty regards the moment of the occurrence and, maybe, the exact details of the impact.

Crisis Management approaches the threats mostly from a reactive perspective; it describes actions that need to be put in place in order to reduce as much as possible the negative effects of an event, which is, in general, unexpected.

Risk management approaches the threats from a proactive perspective; it is concerned with identifying and correctly assessing of a possible threat. While risk management is treating risks individually, organizational crisis management is concerned also with identifying the connections between different individual threats, from different organizational areas and levels that, existing together, might add up to become a an increased threat and generate a crisis. From this perspective, crisis management has a more integrative approach.

On the other hand, risk management involves identifying and assessing potential threats and finding the best ways to avoid those threats to materialize, while crisis management involves dealing with threats before, during, and after they have occurred. In 
an extended version of the pre-crisis stage of crisis management, the actions are similar to the ones engaged by risk management.

The process of identifying, assessing and mitigating potential threats as part of the larger crisis management process is called crisis prevention. Implemented within an organization as a continuous process, crisis prevention or risk management will diminish considerably the probability for the organization to face a crisis. The exposure to crises will not decrease to zero, as there is always a certain percentage of risks that can never be completely eliminated, but the chances of avoiding a crisis and recovering after a crisis will be much higher when the organization is adopting a crisis prevention/risk management approach.

In conclusion, we can say that risk management and crisis management are not competing with each other as practices within an organization, rather, they are working together for the same outcome, which is increasing the capacity of an organization to cope in the most efficient way with any possible threat that might put in danger its functionality or even its existence.

There is a strong connection between the risk management and crisis management practices. Both, crisis management and risk management are part of the general domain of organizational management and they both deal with threats that impact the well running of the organization's systems and the wellbeing of its individuals.

\section{Conclusion}

We have explored the consistency in the definition of the critical concept of crisis. We have argued that a large number of definitions existing in the literature do not successfully provide an ex ante approach to such a definition. Such a failure will impact the way the literature define the concept and explore further the crisis management.

We argue that the crisis management is a broader area of expertise than risk management. Starting from the difference between uncertainty and risk, we argue that crisis management raises multiple challenges as compared with risk management as it is more complex, diffuse and challenging.

\section{References}

Dima, M.A. and Vasilache, S. (2016), "Trends in the internationalization of European higher education in a convergence perspective", Management \& Marketing. Challenges for the Knowledge Society, Vol. 11, No. 2, pp. 449-457 DOI: 10.1515/mmcks2016-0008.

Foerster-Pastor, U.S., and Golowko, N. (2018), "The need for digital and soft skills in the Romanian business service industry", Management \& Marketing. Challenges for the Knowledge Society, Vol. 13, No. 1, pp. 831-847, D0I: 10.2478/mmcks-2018-0008.

Heller, V. L. and J. R. Darling (2012) Anatomy of crisis management: lessons from the infamous Toyota Case, European Business Review, vol. 24, no. 2 (pp. 151-168).

Hulsmann, Jorg Guido (1998) Towards a General Theory of Error Cycles, The Quarterly Journal of Austrian Economics, vol. 1, no. 4 (pp. 1-23).

Knight, F. H. (1964) Risk, Uncertainty and Profi”, Augustus M. Kelley, New York;

Kouzmin, Alexander (2008). Crisis Management in Crisis? Administrative Theory and Practice, vol. 30, no. 2 (pp. 155-183). 
Pearson, Christine and Judith Clair (1998) Reframing Crisis Management, The Academy of Management Review, vol. 23, no. 1 (pp. 59-76).

Pollard, D. and S. Hotho (2006) Crises, scenarios and the strategic management process, Management Decision, vol. 44, no. 6 (pp. 721-736).

Shristava, Paul (1987) Preventing Industrial Crises: The Challenge of Bhobal, International Journal of Mass Emergencies and Disasters, vol. 5, no. 3.

PICBE | 968

Telang, A. and Deshpande, A. (2016), "Keep calm and carry on: A crisis communication study of Cadbury and McDonalds", Management \& Marketing. Challenges for the Knowledge Society, Vol. 11, No. 1, pp. 371-379, DOI: 10.1515/mmcks-2016-0003. 